ARTICLE

\title{
Human occupation of northern India spans the Toba super-eruption 74,000 years ago
}

\author{
Chris Clarkson (1) 1,2,3凶 , Clair Harris ${ }^{1}$, Bo Li2 ${ }^{2,4}$, Christina M. Neudorf (10 5 , Richard G. Roberts (1) 2,4, \\ Christine Lane ${ }^{6}$, Kasih Norman ${ }^{2}$, Jagannath Pal ${ }^{7}$, Sacha Jones (1) ${ }^{8,9}$, Ceri Shipton (1) ${ }^{10}$, Jinu Koshy ${ }^{11}$, M.C. Gupta ${ }^{7}$, \\ D.P. Mishra7, A.K. Dubey ${ }^{12}$, Nicole Boivin ${ }^{1,3,13,14}$ \& Michael Petraglia (1) 1,3,13凶
}

India is located at a critical geographic crossroads for understanding the dispersal of Homo sapiens out of Africa and into Asia and Oceania. Here we report evidence for long-term human occupation, spanning the last $\sim 80$ thousand years, at the site of Dhaba in the Middle Son River Valley of Central India. An unchanging stone tool industry is found at Dhaba spanning the Toba eruption of $\sim 74$ ka (i.e., the Youngest Toba Tuff, YTT) bracketed between ages of $79.6 \pm 3.2$ and $65.2 \pm 3.1 \mathrm{ka}$, with the introduction of microlithic technology $\sim 48 \mathrm{ka}$. The lithic industry from Dhaba strongly resembles stone tool assemblages from the African Middle Stone Age (MSA) and Arabia, and the earliest artefacts from Australia, suggesting that it is likely the product of Homo sapiens as they dispersed eastward out of Africa.

\footnotetext{
${ }^{1}$ School of Social Science, University of Queensland, St Lucia, QLD 4072, Australia. ${ }^{2}$ Australian Research Council (ARC) Centre of Excellence for Australian Biodiversity and Heritage, University of Wollongong, Wollongong, NSW 2522, Australia. ${ }^{3}$ Department of Archaeology, Max Planck Institute for the Science of Human History, Kahlaische Strasse 10, Jena 07745, Germany. ${ }^{4}$ Centre for Archaeological Science, School of Earth, Atmospheric and Life Sciences, University of Wollongong, Wollongong, NSW 2522, Australia. ${ }^{5}$ Desert Research Institute, Reno, Nevada 89512, USA. ${ }^{6}$ Department of Geography, University of Cambridge, Downing Place Cambridge, Cambridge CB2 3EN, UK. ${ }^{7}$ Department of Ancient History, Culture and Archaeology, University of Allahabad, Allahabad 211002 Uttar Pradesh, India. ${ }^{8}$ McDonald Institute for Archaeological Research, University of Cambridge, Downing Street, Cambridge CB2 3ER, UK. ${ }^{9}$ Office of Scholarly Communication, Cambridge University Library, West Road, Cambridge CB3 9DR, UK. ${ }^{10}$ Australian Research Council (ARC) Centre of Excellence for Australian Biodiversity and Heritage, Australian National University, College of Asia and the Pacific, Canberra, ACT 0200, Australia.

${ }^{11}$ Department of Ancient History and Archaeology, University of Madras, Chepauk, Chennai 600 005, India. ${ }^{12}$ Department of Ancient Indian History, Culture and Archaeology, Banaras Hindu University, Varanasi, India. ${ }^{13}$ Department of Anthropology, National Museum of Natural History, Smithsonian Institution, Washington, DC 20560, USA. ${ }^{14}$ Department of Anthropology and Archaeology, University of Calgary, Calgary, Canada. ${ }^{凶}$ email: c.clarkson@uq.edu.au; petraglia@shh.mpg.de
} 
ndia is a focus of intense debate concerning the timing of the arrival of Homo sapiens, the material culture signature of modern human occupation, the nature of replacement of archaic populations, and the impact of the $\sim 74 \mathrm{ka}$ YTT volcanic eruption on hominin populations. While the Indian fossil hominin record is non-existent for this key time period, analysis of mitochondrial DNA of contemporary populations of India indicates that the region was an important geographic stepping stone in the colonisation of Australasia by Homo sapiens ${ }^{1}$. At the heart of this debate is the issue of whether Homo sapiens arrived in India prior to the YTT event (dated by ${ }^{40} \mathrm{Ar} /{ }^{36} \mathrm{Ar}$ to $73.88 \pm 0.32 \mathrm{ka}^{1}$ and $\left.75.0 \pm 0.9 \mathrm{ka}^{2}\right)^{2-10}$ with a non-microlithic African MSA technology comprised of Levallois and point technology ${ }^{10-12}$, or entered the subcontinent around 50-60 ka with Howiesons Poort microlithic technology ${ }^{13}$. While this debate is pivotal to understanding the archaeological signature of modern humans throughout the region, the reality is that very few sites in India are dated to the crucial time period between 80 and $50 \mathrm{ka}$, hence reliable evidence with which to test competing hypotheses is scarce. Due to the sparse Pleistocene human skeletal record between Africa and South Asia ${ }^{14,15}$, the debate over the South Asian record is largely focussed on stone tools and the DNA of modern populations, as well as rare finds such as engraved ostrich egg shell and worked osseous tools from a handful of sites ${ }^{13}$.

Here we report detailed descriptions of a rich collection of lithic artefacts from the Dhaba locality, situated on the banks of the Middle Son River in Madhya Pradesh, northern India and comprised of three nearby localities (Dhaba 1, 2 and 3) ${ }^{16}$, together with the associated luminescence age estimates. The Dhaba locality provides a detailed archaeological sequence for the Middle Son Valley in a crucial time range of c.80-40 ka, and is positioned chronologically between the early Middle Palaeolithic/ Late Acheulean sites of Patpara, Nakjhar Khurd, Sihawal and Bamburi 1, dated to c.140->104 ka ${ }^{17,18}$, and the blade-based 'Upper Palaeolithic' technologies recovered from Baghor formation deposits, previously dated from c.39 ka, although the latter age is problematic ${ }^{19,20}$ (see Supplementary Discussion for more detailed discussion and Supplementary Fig. 8 for site locations). In this study, we report infrared stimulated luminescence (IRSL) ages for potassium-rich feldspar (K-feldspar) grains collected from excavated cultural sequences at Dhaba. We use the IRSL ages to frame chronological changes in lithic technology at this site and to place the evidence within the context of the South Asian Palaeolithic and the dispersal of modern humans more broadly $^{21}$

The Dhaba locality is composed of three archaeological excavations (Dhaba 1, 2 and 3) on the north banks of the Son River and west of its confluence with the Rehi River (Figs. 1 and 2$)^{16}$. Each of the three archaeological excavations consisted of a step trench placed into hill slope sediments (Table 1; Figs. 2 and 3). Dhaba 1 (N 24 $\left.29^{\prime} 57.6^{\prime \prime}, \mathrm{E} 82^{\circ} 00^{\prime} 35.0^{\prime \prime}\right)$ was selected as the location of densest Middle Palaeolithic surface artefact concentration, with artefacts visibly eroding from sediments at several points up the slope. Dhaba $2\left(\mathrm{~N} 24^{\circ} 29^{\prime} 55.4^{\prime \prime}\right.$, E $82^{\circ} 00^{\prime}$ $24.5^{\prime \prime}$ ) and Dhaba 3 (N $24^{\circ} 29^{\prime} 56.1^{\prime \prime}$, E $82^{\circ} 00^{\prime} 22.5^{\prime \prime}$ ) were selected for excavation due to the existence of eroding accumulations of Middle Palaeolithic artefacts, and a dense concentration of cryptocrystalline microblade and small flake artefacts higher up the slope at Dhaba 3. Excavations at Dhaba 1 and Dhaba 2 are $\sim 600$ and $\sim 900$ m west of the Rehi-Son River confluence, respectively. The trenches were excavated into colluvial and alluvial sediments overlying Proterozoic sandstone and shale bedrock of the Vindhyan Supergroup ${ }^{22,23}$. Substantial deposits of chemically identified YTT are exposed $\sim 700 \mathrm{~m}$ to the east of Dhaba: at Ghogara, on the northern bank of the Son River ${ }^{24,25}$, and in cliff sections on the east bank of the Rehi River ${ }^{26-28}$.

The step trenches expose pedogenically altered alluvial sands, silts and clays (Fig. 3, Supplementary Table 1). The tops of the step trenches at Dhaba 1 and 2 are $\sim 16 \mathrm{~m}$ above river level. The trench at Dhaba 1 reveals a coarsening-upward sequence of floodplain clays, silts and sands with angular sandstone and shale pebbles, carbonate nodules and rhizoliths. These floodplain sediments overlie angular limestone, sandstone and shale boulders derived from the underlying bedrock (Fig. 3). The trench at Dhaba 2 exposes floodplain clays, silts and sands containing carbonate nodules and a few angular pebbles that overlie shale bedrock. Dhaba 3 is $\sim 1 \mathrm{~km}$ west of the Rehi-Son River confluence and consists of a $\sim 3$-m-deep trench $\sim 21 \mathrm{~m}$ above river level that is dug into the southeastern facing slope of a hill composed of colluvial silts, sands and gravels overlying decomposing sandstone and shale bedrock. The estimated thickness of the colluvial sediments at the top of the hillock is $\sim 5 \mathrm{~m}$. The trench exposes silty sands and pebble gravel with angular sandstone and shale clasts. The hillock is separated from a neighbouring sandstone and shale bedrock ridge, which rises to the west to over $40 \mathrm{~m}$ above river level, by south- and southeastdraining gullies that feed into a channel, which, in turn, drains into the Son River. An 10-m high Holocene terrace composed of sands and silts abuts the north bank of the Son River ${ }^{16,28}$. This terrace overlies large, angular quartzite boulders that are intermittently exposed for $\sim 100 \mathrm{~m}$ along the riverfront. Some of these boulders show the removal of large flakes using hard hammer percussion; possibly for the manufacture of quartzite Acheulean cleavers that have been recovered from some sites in the region.

The Dhaba localities together provide evidence of long-term human occupation spanning the last $\sim 80$ thousand years. Occupation spans the Toba eruption and the stone tool industry shows no significant change in technology until the introduction of microlithic technology $\sim 48 \mathrm{ka}$. The lithic industry from Dhaba strongly resembles Middle Stone Age stone tool assemblages from Africa, Arabia and Australia, here interpreted as the product of Homo sapiens as they dispersed eastward out of Africa.

\section{Results}

IRSL chronology. Thirteen sediment samples from the Dhaba locality were dated using a multiple-elevated-temperature postinfrared IRSL (MET-pIRIR) method ${ }^{29}$, described in Methods below. The oldest ages are for Dhaba 1 (Supplementary Table 2) and are stratigraphically consistent with an upper and lower deposit, which mantle the steep slope. The lower unit has IRSL ages of $78.0 \pm 2.9$ and $79.6 \pm 3.2 \mathrm{ka}$ (Fig. 3a), while the upper unit has IRSL ages of $70.6 \pm 3.9$ and $65.2 \pm 3.1 \mathrm{ka}$ (Supplementary Table 2). Dhaba 2 was deposited between $55.0 \pm 2.7$ and $37.1 \pm$ $2.1 \mathrm{ka}$ (Fig. 3c), while Dhaba 3 has ages of between $55.1 \pm 2.4$ and $26.9 \pm 3.8 \mathrm{ka}$ (Fig. 3d). The Dhaba sequence, therefore, began accumulating just prior to the YTT event, with only a small likelihood of occuring later, taking the age uncertainties into consideration ( $p$-values of $<0.08$ and $<0.15$ assuming a true age for the eruption of 73.88 or $75.0 \mathrm{ka}$, respectively). Sediment deposition continued until close to the time of the Last Glacial Maximum, making this a unique locality in South Asia with an industrial sequence that stretches from before the YTT event to the microlithic transition.

Interestingly, six glass shards were found at Dhaba 1 in deposits dated to between $79.6 \pm 3.2$ and $65.2 \pm 3.1 \mathrm{ka}$ (Fig. 3a, see Supplementary Note 1 and Supplementary Table 4), which is consistent with the known date of the YTT event and the widespread presence of YTT in India and the Middle Son Valley $^{2-10,30}$. However, we cannot rule out contamination by 




Fig. 1 Archaeological sites mentioned in the text overlaid on a digitial elevation model of the Eurasian and South Asian landmasses at -60-m sea level consistent with MIS3/4. Topographic and bathymetric data was obtained from GEBCO 2014 Grid, version 20150318, http://www.gebco.net. Top: Archaeological sites associated with modern humans between Africa and Australia dated $>50$ ka. 1. Panga ya Saidi; 2. Mumba; 3. Porc Epic; 4. Nazlet Khater; 5. Al Wusta; 6. Jubbah; 7. Qafzeh; 8. Skhul; 9. Dhofar; 10. Jebel Faya; 11. Katoati; 12. Mehtakheri; 13. Dhaba; 14. Jwalapuram; 15. Denisova Cave; 16. Tam Pa Ling; 17. Fuyan Cave; 18. Lida Ajer; 19. Madjedbebe. Bottom: Location of key sites in India and modelled routes of dispersal (dashed orange lines and arrows) from west to east, after Field and colleagues $^{21}$.

human agency as a possible source of these few shards at Dhaba 1 , given the presence of thick YTT deposits at nearby sites that were visited by some of the same researchers.

Stone artefacts. The stone artefact sequence at the three Dhaba excavations spans 55 thousand years, from about 80 to $25 \mathrm{ka}$, with several distinct pulses in artefact discard (Supplementary Table 1). The sequence is characterised by three major technological phases (Table 1).
The Dhaba 1 assemblage accumulated between around 80 and $65 \mathrm{ka}$, and contains a predominantly recurrent Levallois core assemblage that includes centripetal, bidirectional and unidirectional recurrent Levallois cores, Levallois flakes, Levallois points, Levallois blades, notches and scrapers (Fig. 4, Supplementary Figs. 5, 7); these tools are made almost exclusively on chert, mudstone and silicified limestone (Fig. 5a). Multiplatform and bidirectional cores and redirecting flakes are also present. Flakes show predominantly strongly radial and weakly radial flake scar patterning, consistent with centripetal core reduction (Fig. 5b, 

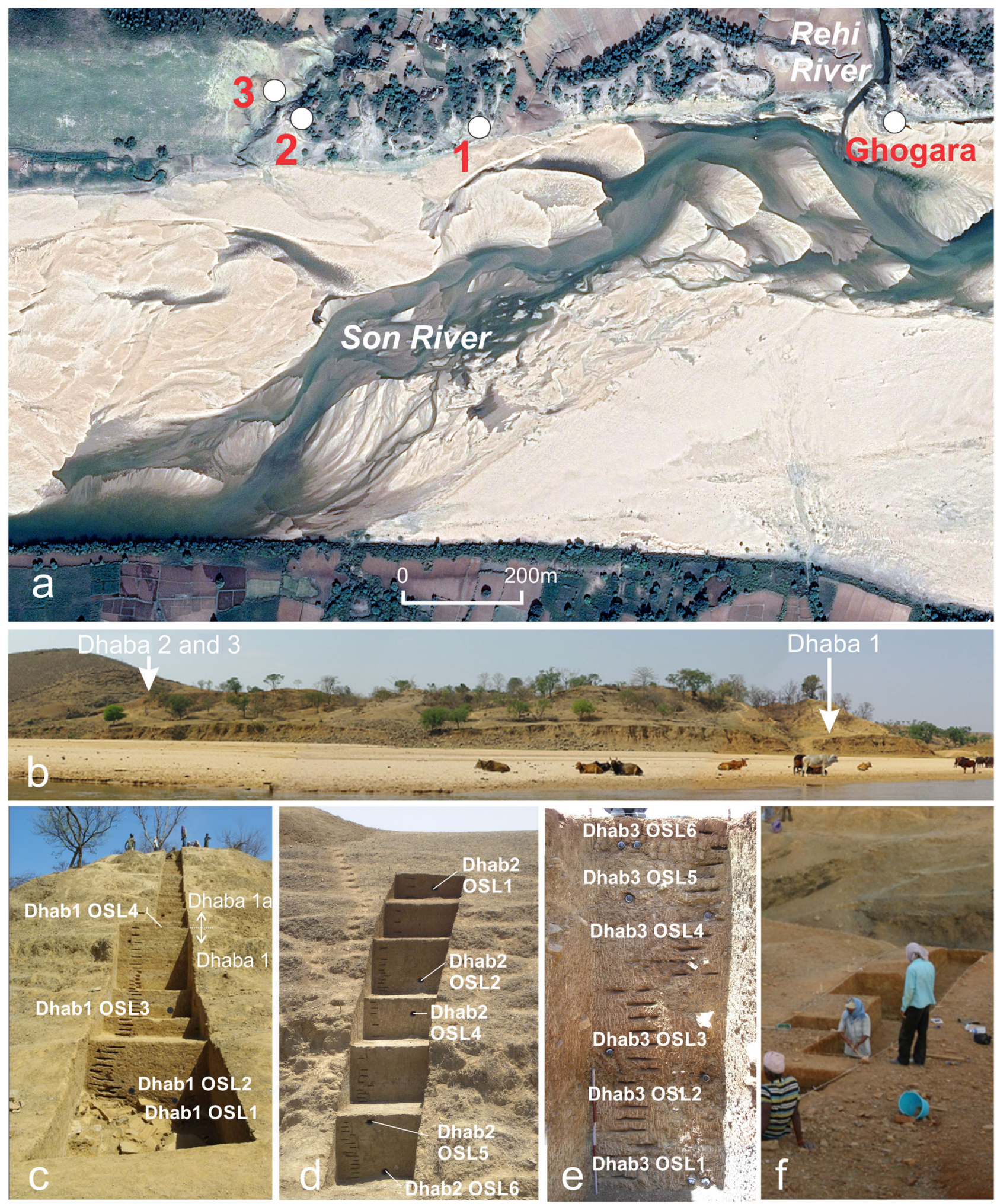

Fig. 2 Dhaba site location and excavation sections. a Satellite image of the Son River showing the Rehi confluence and location of the Dhaba excavations (image courtesy of GoogleEarth, image date 11/26/2015, Image (c) 2019 CNES/Airbus). b View of the Dhaba locality from the Middle Son river bed (photo Courtesy of Michael Haslam). c Dhaba 1 trench (below), Dhaba 1A trench (above), and locations of IRSL samples. d Dhaba 2 trench showing IRSL sample locations. e Dhaba 3 section showing IRSL sample locations. $\mathbf{f}$ View of Dhaba 3 trench during excavation.

Supplementary Figs. 5, 7). Red ochre is also present in the Dhaba 1 assemblage (Fig. 4f, g).

Levallois technology continues to dominate the Dhaba 2 and 3 assemblages between about 55 and $47 \mathrm{ka}$ (strata K and J at Dhaba
3, and strata I to E at Dhaba 2) when artefact deposition peaks. Levallois technology is absent from Dhaba above stratum E, dated to $47.5 \pm 2.0 \mathrm{ka}$. Microlithic technology appears at c. $48 \mathrm{ka}$ in stratum D at Dhaba 2 and stratum $J$ in Dhaba 3, with 


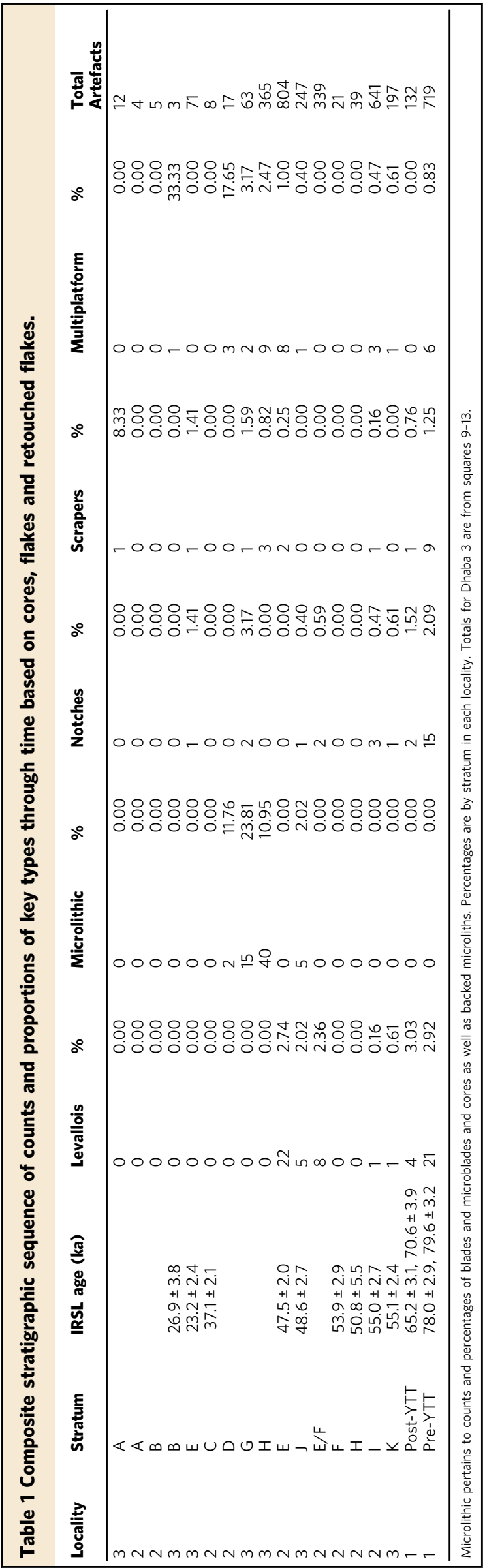

microblades, backed artefacts and unidirectional and bidirectional microblade cores all appearing in these strata (Fig. 4h, i, n, o, t u, Supplementary Fig. 6). Quartz is the dominant raw material throughout this microlithic phase, followed by agate (Fig. 5a). Flakes continue to show predominantly centripetal flake scar patterning until the microlithic change (strata $2 \mathrm{D}$ and $3 \mathrm{G}$ and $3 \mathrm{H}$ ), when proximal and bidirectional scar patterning becomes the dominant dorsal morphology (Fig. 5b).

By c. $37 \mathrm{ka}$, artefact discard drops dramatically at Dhaba 2 and 3 , and very few microlithic artefacts are found after this time (above strata 3C and 2D). Agate and chalcedony are the most common raw materials throughout this final period of site occupation, and flakes show mainly bidirectional and proximal flaking orientations (Fig. 5b).

The broad changes in the proportions of key types through time shown in Table 1 are statistically significant (Pearson chisquare $=2109 ; N=864 ; p=<0.0005$ one-sided).

\section{Discussion}

The luminescence ages of the Dhaba locality contribute a key missing component in the Middle Son valley chronological sequence, as well as a rare glimpse into the nature of technological change in India between about 80 and $24 \mathrm{ka}$. The sequence closely mirrors that at Jwalapuram in southern India ${ }^{31-33}$, showing a change from recurrent Levallois technology to increasing use of single and multiplatform technology and, then, the manufacture of microlithic assemblages. The technological changes in both the Middle Son and Jurreru River valleys appear to be stepwise and involve broad and statistically significant changes in raw material selection, changing retouch strategies (from scrapers and points to backed artefacts), systematic shifts in core reduction technology, and the introduction of new retouched artefact forms such as backed microliths as Levallois technology disappears ${ }^{31,32}$. Some overlap between Levallois and microlithic technology is also present at Dhaba, with both microlithic and Levallois technology occurring together in stratum J of Dhaba $3(48.6 \pm 2.7 \mathrm{ka})$ and stratum E of Dhaba $2(47.5 \pm 2.0 \mathrm{ka})$. The Dhaba sequence presents stratified assemblages spanning the YTT event, and the transition from Levallois to microlithic industries. Other key sites in India also document gradual changes from the Middle Palaeolithic through to the microlithic, such as Bhimbetka ${ }^{34}$ and Patne $^{35}$, though neither of these sites has been well-dated using modern geochronological techniques and are not known to contain any traces of YTT.

We find that the sequence offered by Dhaba further cements the notion that MSA-like technologies were present in India before and after the YTT eruption ${ }^{10,31,36}$. Lithic technology evolved away from Levallois towards lamellar core reduction systems, and finally saw the introduction of the microlithic (in the form of backed microblades) most likely long after Homo sapiens first appeared in the region ${ }^{31,32}$.

Recent genetic analyses point to a modern human exit from Africa around $70-52 \mathrm{ka}^{37,38}$, in which all contemporary nonAfrican peoples branched off from the same ancestral population that left Africa, possibly with minor genetic contributions from an earlier modern human migration wave 37,39 . Fossil evidence supports earlier dispersals of Homo sapiens, with our species present in Greece and the Levant by $200-185 \mathrm{ka}^{40,41}$, Arabia by $\sim 85 \mathrm{ka}^{42}$, China before $\sim 80 \mathrm{ka}^{43}$ and Southeast Asia by $73-63 \mathrm{ka}^{44}$, in association with MSA/Middle Palaeolithic technology (where stone artefacts are present). Recent finds from Madjedbebe in northern Australia also document a modern human presence at the eastern end of the 'southern arc' dispersal route by $65 \pm$ $6 \mathrm{ka}^{45}$, indicating that groups of Homo sapiens likely colonised South Asia prior to this time. The strong connections between 
a

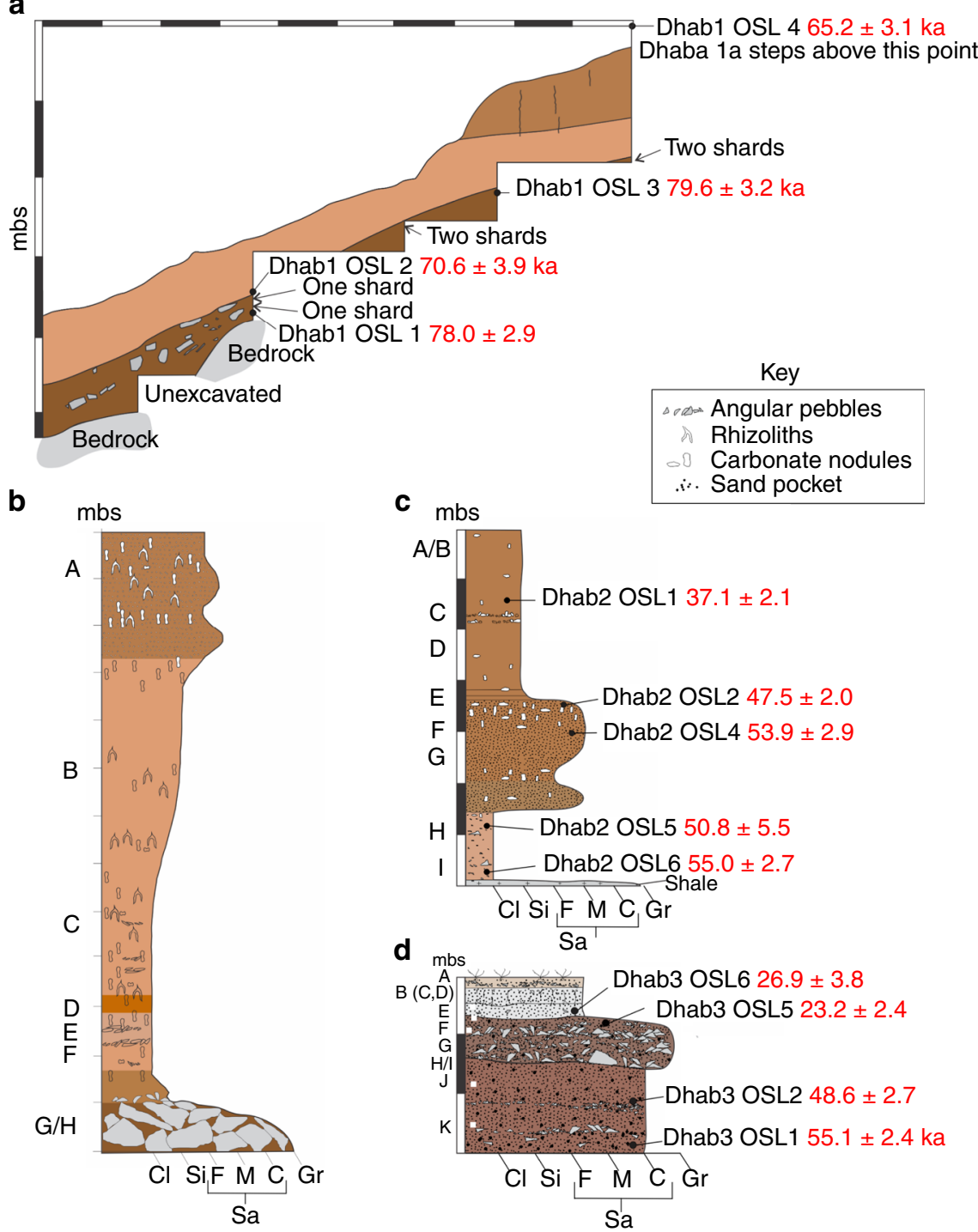

Fig. 3 Dhaba stratigraphy and chronology. a Dhaba 1 profile showing location of IRSL ages and cryptotephra shards. The upper $7.88 \mathrm{~m}$ of Dhaba $1 \mathrm{a}$ are not shown. Note all glass shards are found at or below the boundary between the yellow-brown clay-rich layer and the overlying light yellowish brown silt layer and are bracketed by ages of 78 and $71 \mathrm{ka}$. b Dhaba 1 sediment log. $\mathbf{c}$ Dhaba 2 sediment log and IRSL ages. d Dhaba 3 sediment log and IRSL ages. Cl = clay, $\mathrm{Si}=$ silt, $\mathrm{Sa}=$ sand ( $\mathrm{F}, \mathrm{M}$ and $\mathrm{C}$ are fine, medium and coarse, respectively), $\mathrm{Gr}=$ gravel, $\mathrm{mbs}=$ metres below surface. Alphabetial references are to stratigraphic layers. Refer to Supplementary Table 1 for detailed sedimentary descriptions.

Aboriginal and South Asian modern human genomes is consistent with dispersal through South Asia ${ }^{1,46-48}$ and admixture with Denisovans somewhere along this route ${ }^{49,50}$. The presence of centripetal core and retouched point technology-and the absence of microlithic technology-in northern Australia at c. $65 \mathrm{ka}$ makes connections to Southeast Asia, India and East Africa much stronger than previously proposed ${ }^{11,42}$. These technologies co-occur in sites east of Africa dated to between about 100 and $47 \mathrm{ka}$, suggesting they were likely stepping stones along the southern arc dispersal route ${ }^{11}$. This hypothesis is further supported by quantitative comparisons of core technologies from along this route that point to technological continuity between Africa and Australia $10,11,31$. Modern human dispersal out of Africa, and more importantly east of Arabia, must therefore have taken place before $\sim 65 \mathrm{ka}$, so cultural and fossil evidence from sites dating to this period will be important for future tests of this hypothesis, notwithstanding the fact that population contractions and turnovers may have also occurred. The Dhaba locality serves as an important bridge linking regions with similar archaeology to the east and west.

\section{Methods}

Excavation. Dhabas 1-3 were excavated under permit from the Archaeological Survey of India (No. F.1/36/2008-EE). All trenches was excavated simultaneously by several teams in $1 \times 1 \mathrm{~m}$ pits arranged as step trenches down the slope at each locality. Excavation trenches were placed in areas where artefacts were eroding from the slope in high density. Dhaba 1 was excavated in 4 lower steps and 1a was excavated in 12 upper steps covering a total elevation of 9-22 $\mathrm{m}$ above river level. Dhaba 2 was excavated in six steps covering a total elevation of $21-28 \mathrm{~m}$ above river level. The Dhaba 3 trench is located $25-30 \mathrm{~m}$ above river level and was $18-\mathrm{m}$ long. Each pit was excavated in spits of $\sim 10$-cm depth, with levels taken after each spit using a line level. All excavated sediments were passed through a $5 \mathrm{~mm}$ sieve and all artefacts recovered. The weight of the matrix removed during excavation was recorded and all finds were placed in clip seal plastic bags and labelled with provenance details.

Artefact analysis. All artefacts were washed and taken to the archaeology laboratory in the Department of Ancient History, Culture and Archaeology at the 




a



b


k
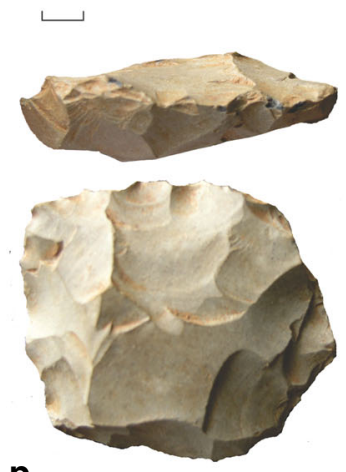

p

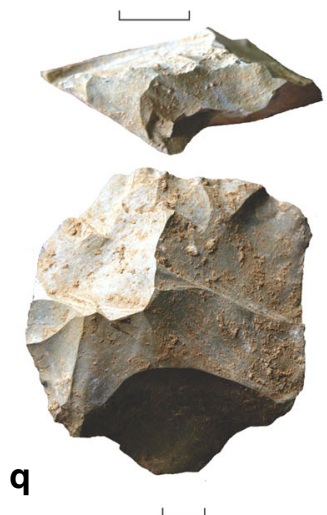

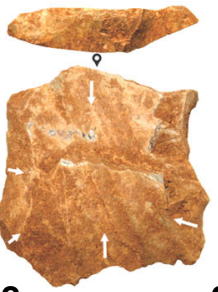

C

I
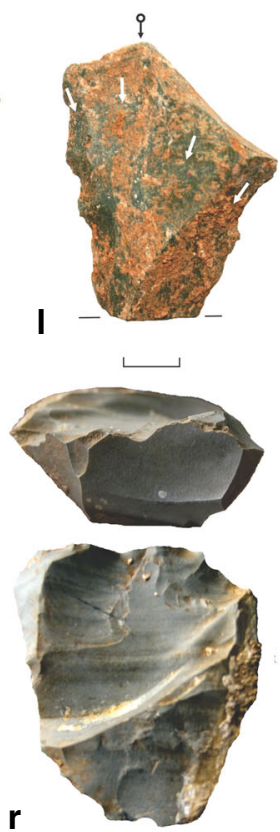

f



g



m



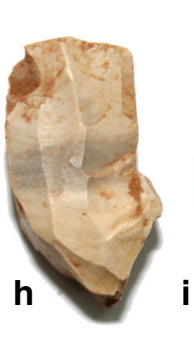
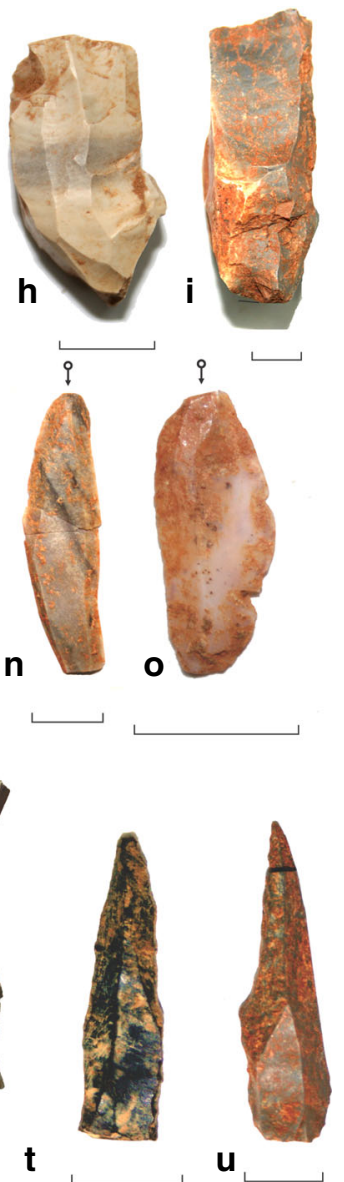

Fig. 4 Key artefact types at Dhaba from 80 to $\mathbf{2 5}$ ka. a-c Levallois flakes, Dhaba 1 and 2. d, e Levallois blades, Dhaba 1. f, g Ochre, Dhaba 1. h, i Microblade cores, Dhaba 3. j Notched scraper, Dhaba 1. k-m Levallois points, Dhaba 1 and 2. n, o Agate and chert microblades, Dhaba 3. p-s Recurrent Levallois cores, Dhaba 1-3. t, u Backed microliths, Dhaba 3. White arrows indicate scar directions. Black arrows with circles indicate impact points.

University of Allahabad for analysis. Each artefact was first classified into technological categories such as core, flake, flaked piece and retouched flake and ascribed typological categories where appropriate. All artefacts were assigned individual specimen numbers, weighed, measured with digital callipers and photographed. All information was entered into a relational database along with detailed provenance information for each artefact. Artefact measurement protocols follow those described in Clarkson et al. ${ }^{31}$. All cores were scanned in three dimensions using a NextEngine laser scanner and a select set of core measurements taken for each ${ }^{31}$. Select artefacts were illustrated using conventional archaeological illustration techniques and protocols.

IRSL dating. Sediment samples were collected by hammering opaque plastic tubes $(5 \mathrm{~cm}$ in diameter) into the cleaned section face. The tubes were removed and wrapped in light-proof plastic for transport to the Luminescence Dating Laboratory at the University of Wollongong. Under dim red laboratory illumination, each sample was treated using standard procedures to extract sand-sized grains of Kfeldspar ${ }^{51,52}$. The samples were routinely treated with solutions of $\mathrm{HCl}$ acid and $\mathrm{H}_{2} \mathrm{O}_{2}$ to remove carbonates and organic matter, respectively, and then dried. Different grain size fractions in the range of $90-212 \mu \mathrm{m}$ were obtained by dry sieving, and the K-rich feldspar grains separated using a heavy liquid solution of sodium polytungstate with a density of $2.58 \mathrm{~g} / \mathrm{cm}^{3}$. The separated grains were etched using $10 \% \mathrm{HF}$ acid for $\sim 40$ min to clean the surfaces of the grains and reduce the thickness of the alpha-irradiated layer around the grain surface. IRSL measurements of the K-feldspar grains were made on an automated Risø TL-DA20 reader equipped with IR diodes $(875 \mathrm{~nm})$ for stimulation, which delivered $\sim 135 \mathrm{~mW} / \mathrm{cm}^{2}$ total power to the sample position ${ }^{53}$. Irradiations were carried out within the reader using a ${ }^{90} \mathrm{Sr} /{ }^{90} \mathrm{Y}$ beta source. The IRSL signals were detected using a photomultiplier tube with the stimulated luminescence passing through a filter pack containing Schott BG-39 and Corning 7-59 filters, which provides a blue transmission window $(320-480 \mathrm{~nm})$. Aliquots containing several hundred grains ( $\sim 5 \mathrm{~mm}$ in diameter) were prepared by mounting the grains as a monolayer on a 9.8-mm-diameter aluminium disc using "Silkospray" silicone oil as an adhesive.
The dose rates were determined from field measurements of the gamma dose rate, laboratory measurements of the beta dose rate using the sediment samples recovered from each tube hole, and published estimates of the cosmic-ray dose rate and the internal dose rate (due to ${ }^{40} \mathrm{~K}$ and ${ }^{87} \mathrm{Rb}$ contained within the K-feldspar grains). The dosimetry data for all samples are summarised in Supplementary Table 2. The gamma dose rates were measured using an Exploranium GR-320 portable gamma-ray spectrometer, which is equipped with a 3 -inch diameter $\mathrm{NaI}$ (Tl) crystal calibrated for $\mathrm{U}$, Th and $\mathrm{K}$ concentrations using the CSIRO facility at North Ryde. At each sample location, 3-4 measurements of $900 \mathrm{~s}$ duration were made of the gamma dose rate at field water content. The external beta dose rate was measured by low-level beta counting using a Risø GM-25-5 multicounter system ${ }^{54}$ and referenced to the Nussloch Loess (Nussi) standard ${ }^{55}$. These external components of the total dose rate were adjusted for sample water content, assuming a value of $7 \pm 2 \%$ for all samples (based on the measured (field) water content of each sample, which ranged from 2 to $5 \%$, and making an allowance for collection of samples during the dry season and partial drying out of the exposed sections prior to sample collection); the assigned uncertainty captures the likely range of time-averaged values for the entire period of sample burial. The minor contribution from cosmic rays was estimated from the burial depth and water content of each sample, and the latitude, longitude and altitude of the Dhaba sites ${ }^{56}$. The internal dose rate was estimated by assuming ${ }^{40} \mathrm{~K}$ and ${ }^{87} \mathrm{Rb}$ concentrations of $13 \pm 1 \%$ and $400 \pm 100$ p.p.m., respectively ${ }^{57-59}$.

The MET-pIRIR procedure $29,60-62$ was applied to determine equivalent dose $\left(D_{\mathrm{e}}\right)$ of our samples. The IRSL signals of both regenerative and test doses were measured by increasing the stimulation temperature from 50 to $300{ }^{\circ} \mathrm{C}$ in steps of $50{ }^{\circ} \mathrm{C}$. A preheat at $320^{\circ} \mathrm{C}$ for $60 \mathrm{~s}$ was applied after both regenerative and test doses. At the end of the IRSL measurements for each test dose, a 'hot' IR bleach at $325^{\circ} \mathrm{C}$ for $100 \mathrm{~s}$ was conducted to minimise the residual signal preceding the next measurement cycle. The full experimental procedure is summarised in Supplementary Table 3.

Typical IRSL and MET-pIRIR decay curves and dose response curves (DRCs) for one aliquot of sample Dhab1-OSL4 are shown in Supplementary Fig. 1a, b, respectively. The intensities of the IRSL and MET-pIRIR signals for all the samples 

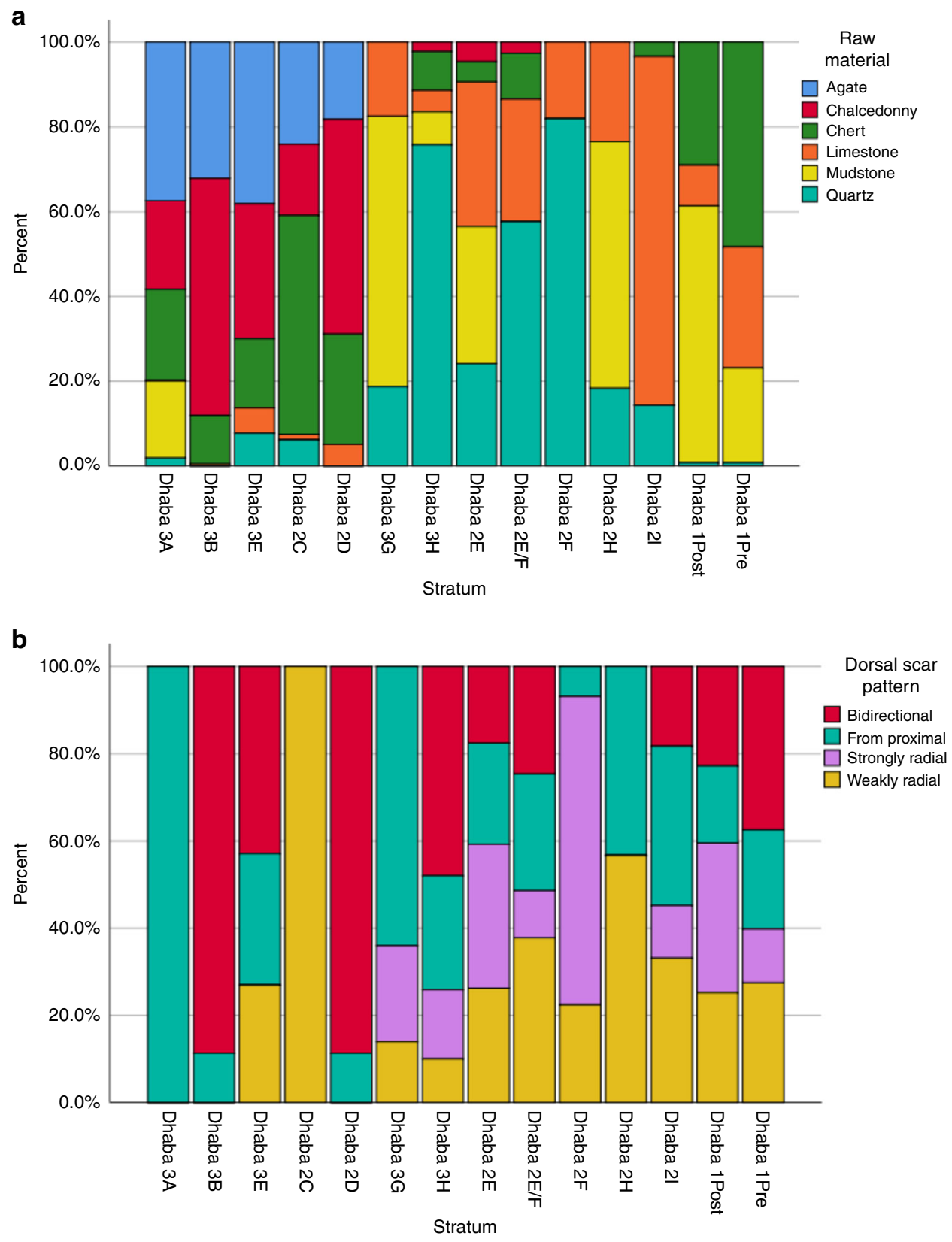

Fig. $\mathbf{5}$ Key raw material and technological changes at Dhaba from $\mathbf{8 0}$ to $\mathbf{2 5}$ ka (left to right = younger to older). a Raw material changes as a proportion of all artefacts by stratum (Pearson chi-square $=892.4 ; N=9 ; N=3512 ; p=<0.005$ ). $\mathbf{b}$ Changes in proportions of scar patterning for all complete flakes by stratum (Pearson chi-square $=37.02 ; \mathrm{df}=9 ; N=797 ; p=<0.005$ one-sided). Bidirectional scar patterns originate from the proximal (platform) and distal ends of the core or flake. Proximal scar patterns originate from the proximal/platform end only. Strongly radial scar patterns originate in a centripetal pattern around the margins of the flake or core, while weakly radial scar patterns are those with scars that originate from several points around the flake or core circumference but are too few in number $(<4)$ to determine a strong centripetal pattern. Source data are provided as a Source Data file.

are very bright and are on the order of $\sim 10^{5}$ counts s$^{-1}$. Different sensitivitycorrected DRCs were observed for the IRSL and various MET-pIRIR signals. These curves were fitted using a single saturating exponential function, which yields characteristic saturation doses of 480, 430, 443, 463, 415 and 308 Gy for the 50,100 , $150,200,250$ and $300^{\circ} \mathrm{C}$ signals, respectively. These results indicate that a natural dose of up to $\sim 800 \mathrm{~Gy}$ can be obtained for the Dhaba samples using the METpIRIR method.

We tested the applicability of the MET-pIRIR procedure to the Dhaba samples using several routine criteria (e.g., recuperation, recycling ratio, dose recovery, anomalous fading and residual dose $)^{61,62}$. Tests of the recycling ratio and

recuperation (i.e., the ratio between the signal responses from a zero regenerative dose and the natural dose) were investigated based on the construction of DRCs for $D_{e}$ estimation. Recycling ratios for all of the samples fell within the range of $1.0 \pm$ 0.1 and recuperation values were mostly $<5 \%$, which are considered acceptable.
For the residual dose test, four aliquots from each of nine samples were bleached by a Dr Hönle solar simulator (model UVACUBE 400 ) for $\sim 4 \mathrm{~h}$. The residual doses associated with the MET-pIRIR signals were then measured; the results for Dhab2-OSL4 are shown in Supplementary Fig. 1c. The IRSL signal at $50^{\circ} \mathrm{C}$ has the smallest residual dose ( 2 Gy), which increases as the stimulation temperature is raised. A residual dose of $\sim 18 \mathrm{~Gy}$ was obtained for the $250^{\circ} \mathrm{C}$ signal, and the highest residual dose ( $\sim 29 \mathrm{~Gy})$ was observed for the $300^{\circ} \mathrm{C}$ signal. The residual doses for the $250^{\circ} \mathrm{C}$ signal are summarised for each sample in Supplementary Table 2; the size of the residual dose represents $5-10 \%$ of the corresponding $D_{\mathrm{e}}$ value of the $250{ }^{\circ} \mathrm{C}$ signal for the Dhaba samples. There is no systematic change in the size of the residual dose with $D_{\mathrm{e}}$ for our samples, which suggests that the non-bleachable traps associated with the residual signal may have been saturated. A simple subtraction of the residual dose from the apparent $D_{\mathrm{e}}$ value may result in underestimation of the true $D_{\mathrm{e}}$ value if the residual signal is 
relatively large compared with the bleachable signal ${ }^{63}$. To estimate the proportion of residual signal to bleachable signal for our samples, 12 aliquots of Dhab1-OSL2, Dhab1-OSL3 and Dhab2-OSL1 were heated to $450^{\circ} \mathrm{C}$ to empty the source traps associated with the residual and bleachable signals. These aliquots were subsequently given different regenerative doses $(165,330$ and $496 \mathrm{~Gy})$ and then bleached using the solar simulator for $4 \mathrm{~h}$ before measuring the residual signal using the MET-pIRIR procedure. The measured residual signals from the different regenerative doses were compared with the total regenerative signals at the same doses. The residual signal corresponds to only $\sim 5 \%$ of the total signal, which is comparable to the residual dose as a proportion of the measured $D_{\mathrm{e}}$. Given the small size of the residual signal relative to the bleachable signal, the simple dosesubtraction approach should give satisfactory results.

We also tested the validity of the dose-subtraction correction and performance of the MET-pIRIR procedure using a dose recovery test. Four aliquots of sample Dhab2-OSL4 were first bleached by the solar simulator for $4 \mathrm{~h}$ and then given a dose of $220 \mathrm{~Gy}$, which was measured as an 'unknown' dose using the MET-pIRIR procedure. The ratios of measured dose to given dose for the IRSL and MET-pIRIR signals are shown in Supplementary Fig. 1d. After correcting for the residual doses shown in Supplementary Fig. 1c, dose recovery ratios of $\sim 0.9$ were obtained for the 50 and $100^{\circ} \mathrm{C}$ signals, and ratios of $1.02 \pm 0.02,1.03 \pm 0.02,1.02 \pm 0.02$ and $1.01 \pm$ 0.03 for the $150,200,250$ and $300^{\circ} \mathrm{C}$ MET-pIRIR signals, respectively. The results of this dose recovery test suggest, therefore, that the combination of MET-pIRIR and simple dose-subtraction procedures can recover a dose consistent with the known dose given to our samples, so we adopted these procedures to estimate the final $D_{\mathrm{e}}$ values and ages for the Dhaba samples.

Previous studies of pIRIR signals have shown that the anomalous fading rate ( $g$ value) depends on the stimulation temperature, with negligible fading rates observed for MET-pIRIR signals at $200^{\circ} \mathrm{C}$ and above $e^{29,60-62}$. No fading correction is therefore required for ages estimated from the high-temperature MET-pIRIR signals. To directly test the absence of significant fading for the samples studied here, we conducted anomalous fading tests on K-feldspar grains from samples Dhab2-OSL1 and Dhab3-OSL1 using a single-aliquot measurement procedure similar to that described by Auclair et al. ${ }^{64}$, but based on the MET-pIRIR measurement procedure in Supplementary Table 3. The $g$-values calculated for the IRSL and MET-pIRIR signals (Supplementary Fig. 1e) show that the fading rate is highest for the $50^{\circ} \mathrm{C}$ IRSL signal (3.2 \pm 0.4 and $4.1 \pm 0.7 \%$ per decade for Dhab2-OSL1 and Dhab3-OSL1, respectively) and decreases as the stimulation temperature is raised. The fading rates for the $200{ }^{\circ} \mathrm{C}$ signal are $<1 \%$ per decade and are consistent with zero for the signals measured at 250 and $300^{\circ} \mathrm{C}$, suggesting that negligible fading or non-fading is achieved at the two highest stimulation temperatures.

Based on the above performance tests, the MET-pIRIR procedure was used to measure the $D_{\mathrm{e}}$ values for all samples. The $D_{\mathrm{e}}$ values obtained for each of the METpIRIR signals are plotted against stimulation temperature $\left(D_{\mathrm{e}}-\mathrm{T}\right.$ plots) for each of the samples from Dhaba 1, 2 and 3 in Supplementary Figs. 2-4, respectively. We also applied a fading correction ${ }^{65}$ to the $D_{\mathrm{e}}$ values based on the $g$-values in Fig. 1e. The fading-corrected $D_{\mathrm{e}}$ values are shown as red squares in Supplementary Figs. 2-4. After applying the fading correction, the fading-corrected $D_{\mathrm{e}}$ values for the 150 and $200^{\circ} \mathrm{C}$ signals are consistent with those obtained at higher temperatures $\left(>200^{\circ} \mathrm{C}\right)$, which have negligible fading rates. This further supports our proposition that the MET-pIRIR procedure can access a non-fading signal for the samples studied here and, hence, the $D_{\mathrm{e}}$ values and ages obtained from the elevated temperature signals should be reliable. More importantly, since the signals measured at different temperatures are bleached at significantly different rates (Supplementary Fig. 1c), the consistency in $D_{\mathrm{e}}$ values across a wide range of stimulation temperatures (i.e., $150-300^{\circ} \mathrm{C}$ ) indicates that our samples had been sufficiently bleached prior to deposition. At lower stimulation temperatures (50 and $100^{\circ} \mathrm{C}$ ), the $D_{\mathrm{e}}$ values are underestimated, even after correcting for fading, which is consistent with the dose underestimation observed at 50 and $100^{\circ} \mathrm{C}$ in the dose recovery test (Supplementary Fig. 1d).

Given the much lower residual dose of the $250^{\circ} \mathrm{C}$ signal compared with the $300^{\circ} \mathrm{C}$ signal (Supplementary Fig. 1c), we consider the $D_{\mathrm{e}}$ values obtained using the $250^{\circ} \mathrm{C}$ signal as the most reliable for the Dhaba samples. The final ages were, therefore, based on the $D_{\mathrm{e}}$ values and associated uncertainties estimated from the $250{ }^{\circ} \mathrm{C}$ MET-pIRIR signal (Supplementary Table 2).

Reporting summary. Further information on research design is available in the Nature Research Reporting Summary linked to this article.

\section{Data availability}

All relevant data used in this paper are available from the authors. Soil and IRSL dating samples are held in the School of Earth and Environmental Sciences at the University of Wollongong, Australia, and in the Department of Archaeology at the Max Planck Institute for the Science of Human History, Germany. All stone artefacts are held in the Department of Ancient History, Culture and Archaeology at the University of Allahabad, India. The source data underlying Fig. 5 are provided as a Source Data file.

Received: 25 March 2019; Accepted: 19 December 2019;

Published online: 25 February 2020

\section{References}

1. Atkinson, Q. D., Gray, R. D. \& Drummond, A. J. mtDNA variation predicts population size in humans and reveals a major Southern Asian chapter in human prehistory. Mol. Biol. Evolution 25, 468-474 (2007).

2. Storey, M., Roberts, R. G. \& Saidin, M. Astronomically calibrated ${ }^{40} \mathrm{Ar} /{ }^{39} \mathrm{Ar}$ age for the Toba supereruption and global synchronization of late Quaternary records. Proc. Natl Acad. Sci. USA 109, 18684-18688 (2012).

3. Mark, D. F. et al. A high-precision ${ }^{40} \mathrm{Ar} /{ }^{39} \mathrm{Ar}$ age for the Young Toba Tuff and dating of ultra-distal tephra: forcing of Quaternary climate and implications for hominin occupation of India. Quat. Geochronol. 21, 90-103 (2014).

4. Rose, W. I. \& Chesner, C. A. Dispersal of ash in the great Toba eruption, $75 \mathrm{ka}$. Geology 15, 913-917 (1987).

5. Acharyya, S. K. \& Basu, P. K. Toba ash on the Indian subcontinent and its implications for correlation of Late Pleistocene alluvium. Quat. Res. 40, 10-19 (1993).

6. Shane, P., Westgate, J., Williams, M. \& Korisettar, R. New geochemical evidence for the Youngest Toba Tuff in India. Quat. Res. 44, 200-204 (1995).

7. Westgate, J. A. et al. All Toba tephra occurrences across peninsular India belong to the 75,000 yr BP eruption. Quat. Res. 50, 107-112 (1998).

8. Pearce, N. J. et al. Individual glass shard trace element analyses confirm that all known Toba tephra reported from India is from the c. 75-ka Youngest Toba eruption. J. Quat. Sci. 29, 729-734 (2014).

9. Pearce, N. J., Westgate, J. A., Gualda, G. A., Gatti, E. \& Muhammad, R. F. Tephra glass chemistry provides storage and discharge details of five magma reservoirs which fed the $75 \mathrm{ka}$ Youngest Toba Tuff eruption, northern Sumatra. J. Quaternary Sci. 256-271 (2019)

10. Petraglia, M. et al. Middle Paleolithic assemblages from the Indian subcontinent before and after the Toba super-eruption. Science 317, 114-116 (2007).

11. Clarkson, C. in Southern Asia, Australia and the Search for Human Origins 76-89 (Cambridge University Press, Cambridge, 2014).

12. Groucutt, H. S. et al. Rethinking the dispersal of Homo sapiens out of Africa Evolut. Anthropol.: Issues, N., Rev. 24, 149-164 (2015).

13. Mellars, P., Gori, K. C., Carr, M., Soares, P. A. \& Richards, M. B. Genetic and archaeological perspectives on the initial modern human colonization of southern Asia. Proc. Natl Acad. Sci. USA 110, 10699-10704 (2013).

14. Dennell, R. \& Petraglia, M. D. The dispersal of Homo sapiens across southern Asia: how early, how often, how complex? Quat. Sci. Rev. 47, 15-22 (2012).

15. Rabett, R. J. The success of failed Homo sapiens dispersals out of Africa and into Asia. Nat. Ecol. Evol. 2, 212-219 (2018).

16. Haslam, M. et al. Dhaba: an initial report on an Acheulean, Middle Palaeolithic and microlithic locality in the Middle Son Valley, north-central India. Quat. Int. 258, 191-199 (2012).

17. Haslam, M. et al. Late Acheulean hominins at the Marine Isotope Stage 6/5e transition in north-central India. Quat. Res. 75, 670-682 (2011).

18. Shipton, C. et al. Generativity, hierarchical action and recursion in the technology of the Acheulean to Middle Palaeolithic transition: a perspective from Patpara, the Son Valley, India. J. Hum. Evolution 65, 93-108 (2013).

19. Jones, S. C. \& Pal, J. N. The Palaeolithic of the Middle Son valley, northcentral India: changes in hominin lithic technology and behaviour during the Upper Pleistocene. J. Anthropological Archaeol. 28, 323-341 (2009).

20. Petraglia, M. D., Ditchfield, P., Jones, S., Korisettar, R. \& Pal, J. N. The Toba volcanic super-eruption, environmental change, and hominin occupation history in India over the last 140,000 years. Quat. Int. 258, 119-134 (2012).

21. Field, J. S., Petraglia, M. D. \& Lahr, M. M. The southern dispersal hypothesis and the South Asian archaeological record: examination of dispersal routes through GIS analysis. J. Anthropological Archaeol. 26, 88-108 (2007).

22. Ray, J. S., Veizer, J. \& Davis, W. J. C, O, Sr and Pb isotope systematics of carbonate sequences of the Vindhyan Supergroup, India: age, diagenesis, correlations and implications for global events. Precambrian Res. 121, 103-140 (2003).

23. Korisettar, R. in The Evolution and History of Human Populations in South Asia 69-96 (Springer, Dordrecht, 2007).

24. Jones, S. C. Palaeoenvironmental response to the $\sim 74 \mathrm{ka}$ Toba ash-fall in the Jurreru and Middle Son valleys in southern and north-central India. Quat. Res. 73, 336-350 (2010).

25. Gatti, E., Durant, A. J., Gibbard, P. L. \& Oppenheimer, C. Youngest Toba Tuff in the Son Valley, India: a weak and discontinuous stratigraphic marker. Quat. Sci. Rev. 30, 3925-3934 (2011).

26. Lewis, L., Ditchfield, P., Pal, J. N. \& Petraglia, M. Grain size distribution analysis of sediments containing Younger Toba tephra from Ghoghara, Middle Son valley, India. Quat. Int. 258, 180-190 (2012).

27. Neudorf, C. M., Roberts, R. G. \& Jacobs, Z. Assessing the time of final deposition of Youngest Toba Tuff deposits in the Middle Son Valley, northern India. Palaeogeogr., Palaeoclimatol., Palaeoecol. 399, 127-139 (2014a).

28. Neudorf, C. M., Roberts, R. G. \& Jacobs, Z. Testing a model of alluvial deposition in the Middle Son Valley, Madhya Pradesh, India-IRSL dating of 
terraced alluvial sediments and implications for archaeological surveys and palaeoclimatic reconstructions. Quat. Sci. Rev. 89, 56-69 (2014b).

29. Li, B. \& Li, S. H. Luminescence dating of K-feldspar from sediments: a protocol without anomalous fading correction. Quat. Geochronol. 6, 468-479 (2011).

30. Smith, V. C. et al. Geochemical fingerprinting of the widespread Toba tephra using biotite compositions. Quat. Int. 246, 97-104 (2011).

31. Clarkson, C., Jones, S. \& Harris, C. Continuity and change in the lithic industries of the Jurreru Valley, India, before and after the Toba eruption. Quat. Int. 258, 165-179 (2012).

32. Clarkson, C., Petraglia, M., Harris, C., Shipton, C. \& Norman, K. in Lithic Technological Organization and Paleoenvironmental Change 37-61 (Springer, Cham, 2018).

33. Petraglia, M. et al. Population increase and environmental deterioration correspond with microlithic innovations in South Asia ca. 35,000 years ago. Proc. Natl Acad. Sci. USA 106, 12261-12266 (2009).

34. Misra, V. N. Prehistoric Culture Sequence of Bhimbetka. Pre-historic Man and His Art in Central India, Pune, 10-16 (1970).

35. Sali, S. A. The Upper Palaeolithic and Mesolithic Cultures of Maharashtra (Deccan College, Pune, 1989).

36. Blinkhorn, J. \& Petraglia, M. D. Environments and cultural change in the Indian Subcontinent: implications for the dispersal of Homo sapiens in the Late Pleistocene. Curr. Anthropol. 58(S17), S463-S479 (2017).

37. Pagani, L. et al. Genomic analyses inform on migration events during the peopling of Eurasia. Nature 538, 238 (2016).

38. Kuhlwilm, M. et al. Ancient gene flow from early modern humans into Eastern Neanderthals. Nature 530, 429-433 (2016).

39. Nielsen, R. et al. Tracing the peopling of the world through genomics. Nature 541, 302 (2017).

40. Harvati, K. et al. Apidima Cave fossils provide earliest evidence of Homo sapiens in Eurasia. Nature 571, 500-504 (2019).

41. Hershkovitz, I. et al. Response to Comment on "The earliest modern humans outside Africa". Science 362, eaat8964 (2018).

42. Groucutt, H. S. et al. Homo sapiens in Arabia by 85,000 years ago. Nat. Ecol. evolution 2, 800 (2018).

43. Liu, W. et al. The earliest unequivocally modern humans in southern China. Nature 526, 696 (2015).

44. Westaway, K. E. et al. An early modern human presence in Sumatra 73,000-63,000 years ago. Nature 548, 322 (2017).

45. Clarkson, C. et al. Human occupation of northern Australia by 65,000 years ago. Nature 547, 306 (2017).

46. Mondal, M., Casals, F., Majumder, P. P. \& Bertranpetit, J. Further confirmation for unknown archaic ancestry in Andaman and South Asia. bioRxiv https://doi.org/10.1101/071175 (2016).

47. Rasmussen, M. et al. An Aboriginal Australian genome reveals separate human dispersals into Asia. Science 334, 94-98 (2011).

48. Reich, D. et al. Denisova admixture and the first modern human dispersals into Southeast Asia and Oceania. Am. J. Hum. Genet. 89, 516-528 (2011).

49. Vernot, B. \& Pääbo, S. The predecessors within. Cell 173, 6-7 (2018).

50. Jacobs, G. S. et al. Multiple deeply divergent Denisovan ancestries in Papuans. Cell 177, 1010-1021 (2019).

51. Wintle, A. G. Luminescence dating: laboratory protocols and procedures. Radiat. Meas. 27, 769-817 (1997).

52. Aitken, M. J. An Introduction to Optical Dating (Oxford University Press, 1998).

53. Bøtter-Jensen, L., Andersen, C. E., Duller, G. A. T. \& Murray, A. S. Developments in radiation, stimulation and observation facilities in luminescence measurements. Radiat. Meas. 37, 535-541 (2003).

54. Bøtter-Jensen, L. \& Mejdahl, V. Assessment of beta dose-rate using a GM multicounter system. Int. J. Radiat. Appl. Instrum. Part D. Nucl. Tracks Radiat. Meas. 14, 187-191 (1988).

55. Jacobs, Z. \& Roberts, R. G. An improved single grain OSL chronology for the sedimentary deposits from Diepkloof Rockshelter, Western Cape, South Africa. J. Archaeological Sci. 63, 175-192 (2015).

56. Prescott, J. R. \& Hutton, J. T. Cosmic-ray contributions to dose-rates for luminescence and ESR dating-large depths and long-term time variations. Radiat. Meas. 23, 497-500 (1994).

57. Huntley, D. J. \& Baril, M. R. The K content of the K-feldspars being measured in optical dating or in thermoluminescence dating. Anc. TL 15, 11-13 (1997).

58. Huntley, D. J. \& Hancock, R. G. V. The Rb contents of the K-feldspars being measured in optical dating. Anc. TL 19, 43-46 (2001).

59. Zhao, H. \& Li, S.-H. Internal dose rate to K-feldspar grains from radioactive elements other than potassium. Radiat. Meas. 40, 84-93 (2005).
60. Li, B. \& Li, S.-H. Luminescence dating of Chinese loess beyond $130 \mathrm{ka}$ using the non-fading signal from K-feldspar. Quat. Geochronol. 10, 24-31 (2012).

61. Li, B., Jacobs, Z., Roberts, R. G. \& Li, S.-H. Review and assessment of the potential of post-IR IRSL dating methods to circumvent the problem of anomalous fading in feldspar luminescence. Geochronometria 41, 178-201 (2014).

62. Roberts, R. G. et al. Optical dating in archaeology: thirty years in retrospect and grand challenges for the future. J. Archaeological Sci. 56, 41-60 (2015).

63. Li, B., Roberts, R. G. \& Jacobs, Z. On the dose dependency of the bleachable and non-bleachable components of IRSL from K-feldspar: improved procedures for luminescence dating of Quaternary sediments. Quat. Geochronol. 17, 1-13 (2013).

64. Auclair, M., Lamothe, M. \& Huot, S. Measurement of anomalous fading for feldspar IRSL using SAR. Radiat. Meas. 37, 487-492 (2013).

65. Huntley, D. J. \& Lamothe, M. Ubiquity of anomalous fading in K-feldspars and the measurement and correction for it in optical dating. Can. J. Earth Sci. 38, 1093-1106 (2001).

\section{Acknowledgements}

We thank the Archaeological Survey of India for permission to conduct the fieldwork, the American Institute of Indian Studies for facilitating this research, and the international team for their contributions to the excavations, especially M. Haslam, A. Crowther and J. Bora. We thank K. Douka for providing comments on a draft of this paper and L. Lewis for conducting cryptotephra lab work. This research was supported by grants from the British Academy (M.P., N.B.), the Leverhulme Trust (M.P., N.B.), the University of Wollongong (B.L.), the European Research Council (M.P.); the Australian Research Council (B.L., C.C., R.G.R.); the McDonald Institute for Archaeological Research (M.P., M. Haslam); and the Max Planck Society (N.B., M.P.).

\section{Author contributions}

J.P., M.P., N.B. and C.C. designed the study. J.P., M.P., C.C., C.H., C.S., J.K., M.C.G., D.P.M., A.K.D. and C.M.N. conducted the fieldwork. C.C., K.N., S.J., B.L., R.G.R. and C.L. wrote the paper. C.C., M.P., N.B. and R.G.R. obtained funding for the study. C.M.N. performed sedimentary analyses. B.L. and R.G.R. carried out IRSL dating. C.L. performed cryptotephra analyses. C.C., C.S. and C.H. analysed the lithic assemblage. C.C., K.N., C.M.N., L.B. and C.H. produced the figures.

\section{Competing interests}

The authors declare no competing interests.

\section{Additional information}

Supplementary information is available for this paper at https://doi.org/10.1038/s41467 020-14668-4.

Correspondence and requests for materials should be addressed to C.C. or M.P.

Peer review information Nature Communications thanks the anonymous reviewers for their contribution to the peer review of this work. Peer reviewer reports are available.

Reprints and permission information is available at http://www.nature.com/reprints

Publisher's note Springer Nature remains neutral with regard to jurisdictional claims in published maps and institutional affiliations.

Open Access This article is licensed under a Creative Commons Attribution 4.0 International License, which permits use, sharing, adaptation, distribution and reproduction in any medium or format, as long as you give appropriate credit to the original author(s) and the source, provide a link to the Creative Commons license, and indicate if changes were made. The images or other third party material in this article are included in the article's Creative Commons license, unless indicated otherwise in a credit line to the material. If material is not included in the article's Creative Commons license and your intended use is not permitted by statutory regulation or exceeds the permitted use, you will need to obtain permission directly from the copyright holder. To view a copy of this license, visit http://creativecommons.org/ licenses/by/4.0\%

(C) Crown 2020 